\title{
The Professional Experiences and Development of Dental Technology Students to Work Based Learning a Five-Year Study
}

\author{
Michael G Reeson ${ }^{1 *}$ \\ ${ }^{1}$ Chief Instructor School of Dental Technology/Associate Lecturer School of Dental Sciences Newcastle \\ University, The Dental Hospital, Richardson Road, Newcastle upon Tyne, England
}

"Corresponding Author: Michael G Reeson, Chief Instructor School of Dental Technology/Associate Lecturer School of Dental Sciences Newcastle University, The Dental Hospital, Richardson Road, Newcastle upon Tyne, England; Email: m.reeson@nhs.net

Received Date: 09-04-2021; Accepted Date: 24-04-2021; Published Date: 30-04-2021

Copyright $^{\oplus} 2021$ by Reeson MG. All rights reserved. This is an open access article distributed under the terms of the Creative Commons Attribution License, which permits unrestricted use, distribution and reproduction in any medium, provided the original author and source are credited.

\begin{abstract}
Background: Work based learning is a fundamental aspect of all healthcare professionals training, as it enables students to develop the knowledge and skills required in their professional practise. Research into work-based learning provides evidence to argue that both obstacles and benefits exist. However, there appears to be no studies that discuss the quality of a work-based placement or the type of work placement students undertake.
\end{abstract}

Objectives: This study investigates the professional experiences and development of dental technology students to work-based learning placements as part of their three-year full-time course in dental technology.

Methods: Students in year two of the course undertook hospital departmental and commercial dental laboratory work based placements over one academic year; each work placement consisted of eight-week blocks with five placement providers. Using a qualitative approach, data sources included work placement diaries and participant feedback.

Results: Six major domains were identified that accurately characterized the participants' beliefs, thoughts and practices. The results indicate the majority of students recognized the benefits of work-based placements in developing relevant skills, knowledge and experience whilst gaining first-hand experience of life in a real working environment. 
Conclusion: It is suggested future dental technology curricula should provide opportunities to develop comprehensive and effective work based learning for students. This needs to be systematically developed within the dental technology curriculum if it is to achieve its desired goal.

\section{Keywords}

Work Based Learning; Dental Technology; Skills; Knowledge; Curricula

\section{Introduction}

Work based learning is a vital component in the training and education of allied healthcare professionals. Learning in the workplace enables students to develop the knowledge, skills and aptitudes required in their professional practise and in so doing develop their professional disciplinary identity [1]. The term work based learning as the name suggests, is delivered mainly in the workplace and is designed to allow the learner to continue developing their skills whilst working and being observed and assessed [2-3]. These programmes come in many different forms and modes of delivery and may also involve completing a technical qualification, relating to the chosen occupation either on 'block' or 'day' release to a college or university with the college or university work being supported by the employer within the practice setting [4]. To ensure that students are adequately supported in their workplace-based learning, many regulatory bodies have produced guidance to set out the standards for learning in practice based settings, such as the General Dental Council's preparing for Practice document for dental education in the United Kingdom [5]. In the United States the U.S. Bureau of Labor Statistics (BLS) reports most dental laboratory technicians are also trained on-thejob, learning new procedures as they advance through training [6]. However, interested individuals can pursue more formal training through certificate and associate's degree programs offered by community colleges and technical schools. Some of these programs may also require students to complete an off-campus clinical experience to provide hands-on learning, similar to a work-based placement in the UK [7]. The advantage of work based learning programmes is that it allows students the opportunity to develop their skills, knowledge and experience whilst gaining first-hand experience of life in a real working environment [8].

The additional skills and knowledge gained during a work-based placement can often be directly applied to student's studies, which can ultimately lead to better grades [9]. One of the important things about these programmes is they provide an opportunity for students to get to grips with meeting deadlines and working as part of a team. As such this allows students the opportunity to gain experience and to develop their own team working and interpersonal skills which will make them a more rounded and attractive candidate for any employer [10]. Work

Reeson MG | Volume 2; Issue 1 (2021) | JDHOR-2(1)-025 | Data Article

Citation: Reeson MG. The Professional Experiences and Development of Dental Technology Students

to Work Based Learning a Five-Year Study. J Dental Health Oral Res. 2021;2(1):1-12.

DOI: http://dx.doi.org/10.46889/JDHOR.2021.2108 
based learning also allows students to question and work with people who work in their chosen career, therefore, staff are able to give students a good and personal insight into what the job entails and what has been developing in the profession [11]. This kind of direct and specialist knowledge will often set those students apart from other candidates looking for a job. Performing well on a work based placement can often lead to a firm job offer at the end of it and regardless of this the contacts acquired and networking done during a placement will put students in contact with people who may well be able to help them enter and progress in their chosen career. Despite the substantial body of literature that exists on work based learning and the potential benefits and obstacles such learning can offer there are still relatively few studies which have examined work based learning for students from the allied healthcare professions [1,11-13]. Indeed the current literature provides little qualitative evidence based on student perceptions [14]. This study explores the professional experiences and development of dental technology students during a prolonged period of work based learning in both a UK Dental Teaching Hospital and commercial dental laboratory setting. Using a qualitative approach, data sources included placement diaries and participant feedback.

\section{Materials and Methods}

The exercise was undertaken by students in the Newcastle upon Tyne Dental Hospital on a three-year dental technology-training programme. Students in year two of the course undertook both hospital and commercial dental laboratory work based placements over one academic year; each work placement consisted of eight-week blocks with five placement providers. Work placements consisted of three hospital laboratories specialising in prosthetics/maxillo facial, crown and bridge/restorative and orthodontic technology and two commercial dental laboratories mainly specialising in removable prosthetics and CAD/CAM technology. Twentythree dental technology students took part in the study over five academic years (five in years 1, 2, 3 and four in years 4 and 5). Data was collected using placement diaries and participant feedback. Each student in the study was asked to keep a diary of their experiences during each week of their work placement. As this was a relatively new experience for most of the students, a prescribed format of the diary was given with question headings designed to assist students to revisit and reflect on what they had experienced during the week, and to identify areas where they encountered problems. Students were free to write as much or as little as they wanted under each heading.

The diary included sections covering the following areas:

- What I did this week

- Who I worked with this week

- What I learnt this week

- How I felt this week

Reeson MG | Volume 2; Issue 1 (2021) | JDHOR-2(1)-025 | Data Article

Citation: Reeson MG. The Professional Experiences and Development of Dental Technology Students

to Work Based Learning a Five-Year Study. J Dental Health Oral Res. 2021;2(1):1-12.

DOI: http://dx.doi.org/10.46889/JDHOR.2021.2108 
- What I enjoyed about this week/did not enjoy about this week

- Anything else

Student appraisal forms were also included in the diaries, which were to be completed at the end of each work-based placement by the laboratory manager/placement supervisor/mentor. The work placement diary was piloted to determine question clarity on a small number of dental technology students who had previously been involved in a period of work based learning. Along with their diaries, students also kept a work experience logbook to record the practical work they undertook on their work placements. Initial student diaries were distributed in September 2013 the final cohort of students to complete the diaries was in September 2018. All placement diaries were completed anonymously. Analysis was mostly restricted to qualitative abridged responses and participant feedback.

\section{Data Analysis}

The primary source of data for each participant was the student's work placement diary. Thematic content analysis was used to identify themes and categories that emerge from the data [15]. This involved the researcher reading all the transcripts from the diaries and making notes of words, or short phrases that sum up what is being said in the text. In the second stage, all the words and phrases are then worked through to look for duplications, thus reducing the number of categories. Once this second list has been compiled, overlapping or similar categories are refined and reduced in number by grouping them together, this reduced list is then used to build a story that connects each of the categories defined through the initial coding [15]. Finally, to validate the data, participant feedback was used. Here a list of central concepts and excerpts of the findings were returned to an invited group of participants in order for them to validate, or refute, the researcher's interpretation of the data.

Table 1 shows the diary questions, the corresponding major domain that each addresses and the themes arising out of the data saturation. The key overarching elements arising from both the domains and themes from the diaries are subsumed under the following headings: knowledge and skills, teamwork, apprehension/awkwardness and motivation. These four key headings are linked to their respective domain/themes in the table. 


\begin{tabular}{|c|c|c|c|}
\hline Questions & Domain & Themes & Headings \\
\hline What I did this week & Learning & Techniques & $\begin{array}{c}\text { Knowledge and } \\
\text { Skills }\end{array}$ \\
\hline $\begin{array}{c}\text { Who I worked with } \\
\text { this week }\end{array}$ & Collaboration & $\begin{array}{c}\text { Involvement } \\
\text { Interaction }\end{array}$ & Teamwork \\
\hline $\begin{array}{c}\text { What I learnt this } \\
\text { week }\end{array}$ & Methods & Processes & $\begin{array}{c}\text { Knowledge and } \\
\text { skills }\end{array}$ \\
\hline $\begin{array}{c}\text { How I felt this week } \\
\text { What I enjoyed } \\
\text { about this week/did } \\
\text { not enjoy about this } \\
\text { week }\end{array}$ & Feelings & Concern & $\begin{array}{c}\text { Apprehension } \\
\text { and } \\
\text { Awnieviomardness }\end{array}$ \\
\hline Anything else & Opportunities & Accomplishment & $\begin{array}{c}\text { Knowledge and } \\
\text { skills }\end{array}$ \\
\hline
\end{tabular}

Table 1: Emerging themes from placement diaries.

\section{Findings and Discussion}

\section{Knowledge and Skills}

Students' initial experiences reflected the domain of learning and the acquisition of knowledge and skills. Students described some of the basic tasks they initially undertook on their placements such as casting impressions, trimming models and making special trays. However, as the weeks progressed students' were able to undertake more advanced work such as orthodontic appliances, emax pressable crowns and developing their knowledge with CAD/CAM technology as indicated by the following abridged responses, started my Medium Opening Activator and worked on my twin block appliance'. (Hospital laboratory placement)' I stained and glazed my emax crown, and began waxing up a temporary 3 unit bridge'. (Commercial laboratory placement)'designed and scanned some temporary crowns, plus some permanent crowns and bridges' (Commercial laboratory placement).

Research suggests that workplace learning is a very effective way to develop expertise, skills and competence that are highly relevant to a given profession and even more so, to a specific workplace [12]. Here students were able to develop their technical skills and acquire disciplinary knowledge within the specialist disciplines undertaking work which was not the norm [16-18]. 
The nature of this process learning by observing and doing supports the development of tacit knowledge and practical know-how. The importance of tacit knowledge is well acknowledged tacit powers of the mind are decisive and predominant at all levels of human cognition; they represent people's ability to acquire and hold knowledge [19]. Research suggests that reflection enables practitioners to tap into knowledge gained through experiences. The practitioner gains a deeper understanding of the meaning of the experience by bringing to consciousness tacit knowledge [20]. Within the current study student responses suggested that reflection was important to their learning as it allowed them to reflect on their own action and this helped identify gaps in their knowledge and enabled them to discuss problems and issues regarding their experiences on placement. For example, one student reported that having now experienced working in one of the specialist disciplines he would be better prepared next time, "I would make myself more aware of the work involved before I go to the next placement". (Commercial laboratory placement). There is a growing expectation that future technologist's will require a higher level of technical skills to work with advanced technologies such as $\mathrm{CAD} / \mathrm{CAM} / \mathrm{AM}$ applications in the modern dental laboratory. Due to the pace of technological change and increasing specialisms, it is argued that the training of such higher-level skills can be more effectively delivered in the workplace itself [21].

Apart from the acquisition of profession specific skills, learning in the workplace can also improve socialisation through interaction and motivation, which also encourages learners to remain in education and complete their studies [22,23]. Students also described some of the 'softer skills' they had developed such as time management, communication and problem solving as indicated by the following abridged responses [24]; 'I enjoyed being busy. It made me work out my time more efficiently' (Hospital laboratory placement)' feeling more organised with my work asking lots of questions and able to progress' (Commercial laboratory placement)' it was good having lots to do. On occasions I was able to work out how things should be done on my own' (Commercial laboratory placement).

In today's labour market, communication, teamwork and problem solving are more important than ever before, therefore, work based learning gives students the opportunity to develop such skills and helps to build the confidence they need to reflect on and learn from their experiences [25].

\section{Teamwork}

There was clear evidence to suggest that collaboration and teamwork were a gradual process. All students had experienced some form of team working and in most cases; this had been a positive experience. Students found members of staff very helpful and supportive and recognised the importance of good communication and the need to be open to other's advice and opinions. Students reported in their diaries that with specific tasks they had worked with

Reeson MG | Volume 2; Issue 1 (2021) | JDHOR-2(1)-025 | Data Article

Citation: Reeson MG. The Professional Experiences and Development of Dental Technology Students

to Work Based Learning a Five-Year Study. J Dental Health Oral Res. 2021;2(1):1-12.

DOI: http://dx.doi.org/10.46889/JDHOR.2021.2108 
the more experienced technicians in the laboratory, for example, with regard to colour toning in dentures and CAD/CAM technology indicated by the following abridged responses; 'specific help from the more experienced guys today with colour toning dentures'. (Commercial laboratory placement)' the rep from the CAD/CAM Company the lab use explained all the stages of the scanning process' (Commercial laboratory placement).

Working alongside experienced staff allowed the students to develop their self-confidence and gave them the opportunity to question and work with staff within the different disciplines; here staff and dental company representatives were able to give them a good and personal insight into what the specialisms entail and what has been developing in the profession [10]. This helped the students get a taste of the job roles and day-to-day organisation of the laboratory enabling them to make an informed decision on whether a particular discipline suited their interest. This also facilitated a solid platform for networking which is crucial for building contacts that become indispensable in securing a job in the future [26]. Most students also indicated that their interpersonal skills had improved as a result of their placements. Students felt more confident and were able to talk more authoritatively about the tasks they had undertaken as indicated by the following abridged responses; 'finally feel like I am understanding orthodontics a lot more, wire is getting easier to bend' (Hospital laboratory placement)' very comfortable the atmosphere in the lab is really good and having done a little bit of cons before, I know I'm going to really enjoy it I'm excited to start some more challenging work' (Hospital laboratory placement).

The development of such skills can be a contributory factor towards students being more successful in securing employment upon qualifying and the evidence presented overwhelmingly supports the contention that the completion of a work placement year is associated with enhanced employment $[27,28]$.

\section{Apprehension and Awkwardness}

Students' initial experiences reflected on how they felt uneasy at the beginning of the placement not knowing what was expected of them and it had taken a few weeks for their confidence to develop as indicated by the following abridged responses; 'a bit overwhelming with the quantity of work'. (Commercial laboratory placement), 'a little lost and out of my comfort zone'. (Hospital laboratory placement),' a little out of my depth, not at all confident'. (Commercial laboratory placement). Starting a placement can be very stressful resulting in feelings of inadequacy and high levels of apprehension and anticipatory anxiety [29,30]. More often than not, this anxiety arises due to a lack of information about the various placements and the staff they will be working with rather than the work they would be expected to undertake [31]. Research shows that learners in unfamiliar environments do experience some reduction in self-confidence and increased anxiety [32]. However, after the first few weeks the students'

Reeson MG | Volume 2; Issue 1 (2021) | JDHOR-2(1)-025 | Data Article

Citation: Reeson MG. The Professional Experiences and Development of Dental Technology Students

to Work Based Learning a Five-Year Study. J Dental Health Oral Res. 2021;2(1):1-12.

DOI: http://dx.doi.org/10.46889/JDHOR.2021.2108 
became more confident as indicated by the following abridged responses; 'learning new skills and being able to repeat for practice '(Commercial laboratory placement)' happy with my progress I'm finding things quite easy to pick up ....SO FAR!' (Commercial laboratory placement) 'enjoyed all aspects of this week including working in a new environment and learning a new skill set' (Hospital laboratory placement).

By the end of their placements student's self-confidence and skills had developed as they were given the opportunity to demonstrate their capabilities and to accomplish tasks and resolve problems in a work context as indicated by the following abridged responses; 'sad that it's my last week, but pleased with everything I've managed to get done' (Commercial laboratory placement).

'I have been challenged but fully supported, it's lovely to do something I've not done before and I'm really happy' (Commercial laboratory placement).

Research suggests that the opportunity given to students during a period of work-based training not only improves the quality of learners' work but also their self-confidence, attitude and selfesteem [32-34].

\section{Motivation}

While the majority of the students indicated that their work placement experiences had been extremely valuable and they had acquired new knowledge and skills, a few commented that they had not had sufficient opportunities to do what they considered "worthwhile" work during their placement [17]. Instead, they had been required to do mundane repetitive tasks such as the pouring of impressions, trimming models and special trays as indicated by the following abridged responses; 'really repetitive work asking other staff about other jobs to do'. (Commercial laboratory placement).

'Out of place and a little abandoned, lab really busy'. (Commercial laboratory placement) would like to have a go at more challenging work' (Hospital laboratory placement).

Research has shown work based learning is not effective without quality learning in the workplace [16]. The allocation and structuring of work is central in stimulating learning. The learning process is affected by the way work is organised and the decisions taken by work place supervisors or co-workers on what work is allocated to novices [35]. This suggests that there needs to be better communication between the academic and workplace supervisor to provide "meaningful work" for students on placement i.e., work experiences in which students receive the optimal mix of high levels of support and challenges in the workplace [12,17]. 
In addition, it is important to understand that work placements can raise other inter-personal issues that should be taken into consideration, for example, placements can break down if either the student or any of the staff are uncooperative, rude or hostile, and the experience will be a negative one for all concerned. An unreliable student who is frequently late or absent from work will disappoint an employer, who may refuse to take future students. Therefore, it is important when developing such programmes to be assured there is the support and commitment on the part of the employer providing the work based learning and to make sure students are also aware of their obligation to ensure a successful experience for everyone [36].

\section{Conclusion}

In general, this work has indicated that the majority of students recognized the benefits of work based placements in developing relevant skills, knowledge and experience whilst gaining firsthand experience of life in a real working environment [8]. One of the most important benefits of work-based learning is its potential to provide opportunities for students to learn more about their own abilities. Here students were able to explore their strengths and weaknesses and identify the gaps in their skills. This helped them to draw a comparison between the skills they possess and those required for a specific job/task [25]. Furthermore it encouraged practical application of the knowledge they had acquired at College/University, students being supported in developing these competencies in the workplace and building a portfolio of evidence from the work environment that they have achieved these competences. It also provided them with several soft skills such as interpersonal skills, communication skills, team working and time management [24].

Moreover, it exposed them to the latest technology, which imparts them with specialist knowledge giving them an advantage over students who are perhaps unaware of the current developments in the profession. This will enable them to talk more authoritatively about their chosen profession during job interviews where employers tend to give precedence to students who have considerable background knowledge of their job roles [25]. Undertaking work based learning also teaches students to work within a multicultural environment and interact with people of all ages and social backgrounds. As a result, it helps students to harness the right attitude and boost their self-confidence, which is vital for building a successful career path [25]. Of equal importance, however, was the opportunity it gave to the work-based placement providers, for example, having an extra pair of hands at no extra cost resulting in increased productivity. Close involvement in the delivery of the work based content of the programme and an insight into whether the students had the characteristics needed for the job giving them the opportunity to recruit the most talented people, thereby reducing the cost of external recruitment [32]. At the same time, however, not all students viewed their experiences as wholly successful, but for all, the positive aspects outweighed the negative ones, and none had regretted having undertaken a placement. Furthermore, it was clear the majority of students

Reeson MG | Volume 2; Issue 1 (2021) | JDHOR-2(1)-025 | Data Article

Citation: Reeson MG. The Professional Experiences and Development of Dental Technology Students

to Work Based Learning a Five-Year Study. J Dental Health Oral Res. 2021;2(1):1-12.

DOI: http://dx.doi.org/10.46889/JDHOR.2021.2108 
were aware the development of their skills and knowledge was dependent on what they were prepared to put into the placement themselves. The UK government commissioned Wilson Review (2012) reaffirmed the importance of a work-based placement period to enhance the student learning experience and research evidence presented overwhelmingly supports the argument that the skills, knowledge and abilities gained through completion of a period of work-based learning is associated with enhanced employability and improved performance $[26,27,14,37]$.

This is further reinforced by the requirement of students to demonstrate competence in a range of skills in the learning outcomes stated in the regulatory body's (General Dental Council) Preparing for Practice document [5]. The content and method of dental technology education has been the subject of many criticisms over the years related to the weak links between college/university and the work place, and problems remain in implementing comprehensive and effective work based experiences for students, especially those undertaking full time college/university based programmes. Within the United States, dental technology programs are also faced with serious challenges, including changes in technology, inadequate funding, and a need to develop a curriculum that meets the current needs of the industry [38] This research within a UK dental teaching hospital is the first study to identify some of the issues in developing such work based learning opportunities. Future course design should consider the substantial and growing empirical evidence that the completion of a comprehensive period of work based learning develops specialist and generic skill sets which benefits all parties involved. It is suggested future dental technology curricula should provide opportunities to develop effective and wide-ranging work-based learning for students to achieve a standard of minimal technical competency.

\section{References}

1. Schucan Bird K, Newman M, Hargreaves K, Sawtell M. Workplace-based learning for undergraduate and pre-registration healthcare professionals: A systematic map of the UK research literature 2003-2013. EPPICentre, Social Science Research Unit, UCL Institute of Education, University College London. 2015.

2. Armstrong P, Hughes M. Developing skills: realistic work environments in further education. FEDA, 2000.

3. Department for education and employment, skills for employment division. Building a stronger network: developing the role of national training organisations. Sheffield: DfEE. 2001. [Last accessed on April 28, 2021] www.dfee.gov.uk/consultations/index.cfm?CONID=46

4. Guidance for Trailblazers - Gov.UK [Last accessed on April 28, 2021] https://www.gov.uk/.../BIS-15-355guidance-for-trailblazers-standards-to

5. Preparing for practice dental team learning outcomes for registration. 2015.

6. US Bureau of labor statistics [Last accessed on April 28, 2021] https://www.bls.gov

7. Dental technician education requirements. 2019. [Last accessed on April 28, 2021] https://study.com/articles/Dental_Technician\%3A_Educational_Requirements_for_Becoming_a_Technicia n_in_the_Field_of_Dentistry.html

8. Little B. Undergraduates work based learning and skills development, tertiary education and management. 2000;6:119-35.

Reeson MG | Volume 2; Issue 1 (2021) | JDHOR-2(1)-025 | Data Article

Citation: Reeson MG. The Professional Experiences and Development of Dental Technology Students

to Work Based Learning a Five-Year Study. J Dental Health Oral Res. 2021;2(1):1-12.

DOI: http://dx.doi.org/10.46889/JDHOR.2021.2108 
9. Bullock K, Gould V, Hejimadi M, Lock G. Work placement experience: should I stay or should I go? Higher Education Research and Development. 2009;50:481-94.

10. Benefits of a work placement. [Last accessed on April 28, 2021] http://www.thebigchoice.com/Placements/Advice/Benefits_of_a Work_Placement.html

11. Little B, Harvey L. Learning through work placements and beyond, centre for higher education research and information. Milton Keynes: Open University. 2006:60.

12. ETF Work-based learning: benefits and obstacles. A literature review for policy makers and social partners in ETF partner countries. 2013.

13. Lemanski T, Mewis R, Overton T. An introduction to work-based learning UK physical sciences centre. Department of Chemistry University of Hull. 2011.

14. Jones CM, Green JP, Higson HE. Do work placements improve final year academic performance or do highcalibre students choose to do work placements? Studies in Higher Education. 2017;42:6;976-92.

15. Burnard P, Gill P, Stewart K, Treasure E, Chadwick B. Analysing and presenting qualitative data. Br Dent J. 2008;204:429-32.

16. Darche S, Nayar N, Bracco K. Work based learning in California: Opportunities and models for expansion. Los Angeles: James Irvine Foundation. 2009.

17. Fuller A, Unwin L. Towards expansive apprenticeships: a commentary by the teaching and learning research programme. London: teaching and learning research programme. 2008.

18. Field S, Hoeckel K, Kis V, Kuczera M. Learning for jobs: OECD reviews of vocational education and training, initial report, organisation for economic cooperation and development, Paris. 2009.

19. Polanyi M. The tacit dimension garden city, NY, Doubleday and Co. 1966.

20. Scanlon J M, Care W D, Udod S. Unravelling the unknown of reflection in classroom teaching. J Adv Nursing. 2002;38(2):136-43.

21. Brennan L. Integrating work-based learning into higher education: A guide to good practice. Bolton: University Vocational Awards Council. 2009.

22. Poortman C, IIIeris K, Nieuwenhuis L. Apprenticeship: from learning theory to practice. J Vocational Education and Training. Special issue on apprenticeships as an evolving model of learning. London: Routledge. 2011;63:3.

23. Hughes K, Bailay T, Mechur M. School-to-work: making the difference in education. New York: institute on education and the economy, 2001 Teachers College, Columbia University. 2001.

24. Bridges D. Transferable skills: A philosophical perspective. Studies in Higher Education. 2006;18(1):43-51.

25. Benefits of work experience for students guest blog by Manasa Boggaram. [Last accessed on April 28, 2021] https://www.scotjobsnet.co.uk/blog/blog/benefits-of-work-experience-for-students

26. Mansfield R. The effect of placement experience upon final-year results for surveying degree programmes. Studies in Higher Education. 2011;36(8):939-52.

27. Moores E, Reddy P. No regrets? Measuring the career benefits of a psychology placement year. Assessment and Evaluation in Higher Education. 2012;37(5):535-54.

28. Jack B. Ward changes and stress in student nurses. Nursing Times. 1995;88(10):51.

29. Gray MA, Smith LN. The qualities of an effective mentor from the student nurse's perspective: findings from a longitudinal qualitative study. J Adv Nursing. 2000;32(6):1542-9.

30. Souto Otero M, Hawley J, Nevala AM. (Eds) European inventory on validation of informal and non-formal learning: 2007update. A final report to DG education and culture of the European Commission. Birmingham: ECOTEC.

31. Cahill H A. A qualitative analyse of student nurses' experiences of mentorship. J Adv Nursing. 1996;24:7919.

32. Darche S, Nayar N, Bracco K. Work based learning in California: opportunities and models for expansion. Los Angeles: James Irvine Foundation. 2009. 
33. European Commission. A new impetus for European cooperation in vocational education and training to support the Europe 2010 strategy, COM (2010) 296 final, Brussels.

34. Fuller A, Unwin L. Towards expansive apprenticeships: A commentary by the teaching and learning research programme. London: Teaching and Learning Research Programme. 2008.

35. Eraut M. How professionals learn through work Guildford: SCEPTrE and the University of Surrey. 2007.

36. Bowman K, Stanwick J, Blythe A. Factors pertaining to quality outcomes of shorter duration apprenticeships and traineeships. Leabrooks: National Centre for Vocational Education Research (NCVER). 2005.

37. Wilson T. A review of business-university collaboration. London: Department for Business, Innovation and Skills 2012. [Last accessed on $\quad$ April 2021$]$ https://www.gov.uk/government/uploads/system/uploads/attcahment_data/file/32383/12-610-wilsonreview-business-university-collaboration.pdf

38. Bobich AM, Mitchell BL. Transforming dental technology education: skills, knowledge and curricular reform. J Dental Education. 2017;81(9):eS59-64. 